\title{
Determination of annual generations of Phytomyza orobanchia Kalt. (Diptera: Agromyzidae), using growing degree-days in Alexandria region, Egypt
}

\author{
M. A. S. Al-Eryan*, Amany M. H. Abu-Shall and Alaa H. Ibrahim
}

\begin{abstract}
In Egypt, parasitic weed species, Orobanche crenata Forsk is one of the major constraints to the production of faba bean, which is considered the most important food legume in the country. The broomrape fly, Phytomyza orobanchia Kaltenbach (Diptera, Agromyzidae) is particularly suitable for biological control since it is oligophagous feeding in the larval stage, only on Orobanche species. The objective of the present study is to estimate the number of annual generations of $P$. orobanchia, using growing degree-days (GDD) in Alexandria region, Egypt. Results revealed that development of Phytomyza immature stages (from egg deposition to adult emergence) required 103.5, 90.0, 79.5, and 93.5 DD through 31,20,18, and 16 days for the investigated four generations, respectively. Percentage of infested Orobanche capsules positively increased with increasing accumulated degree-days. A linear model for predicting infested capsules with P. orobanchia through knowing DD was estimated. The constructed model may be used also in predicting Orobanche capsule infestation with P. orobanchia. Results also indicated that estimating the degree-days will help in predicting the occurrence of the first egg laid for P. orobanchia in O. crenata flowers in the field for the first generation and subsequent generations. Knowledge of the Phytomyza activity will provide a prediction for adult emergence and subsequent egg laying and potential damage by larvae according to infestation percent of Orobanche capsules through the successive generations. This may help the biological control programs to justify the required numbers of Phytomyza and adequate time for releases to obtain the maximum destruction of Orobanche seeds.
\end{abstract}

Keywords: Phytomyza orobanchia, Orobanche crenata, Degree-days, Generations, Biological control, Egypt

\section{Introduction}

In Egypt, Orobanche crenata Forsk is one of the major constraints in faba bean productions, which is considered the most important food legume in the country. In the West Nile Delta region, the area infested with $O$. crenata was more than 25,000 feddan (feddan $=4200 \mathrm{~m}^{2}$ ) (Zaitoun et al. 1991). It occurs in about $20 \%$ of the total area cropped with faba bean, of which about half suffers low to moderate infestation (less than 5 spikes per $\mathrm{m}^{2}$ ) and the other half is infested with 5-20 spikes per $\mathrm{m}^{2}$ or more. The loss in faba bean seed yield in El-Beheirah governorate, Egypt was 20,000 tons or about 10 million dollars (Hassanein et al. 1996).

\footnotetext{
* Correspondence: m_a_aleryan@yahoo.com

Applied Entomology and Zoology Department, Faculty of Agriculture, Alexandria University, Alexandria, Egypt
}

Many management strategies have been tried against $O$. crenata and other broomrape species, but few of them have proved reliable and these are just economical in high value agriculture. The strength of broomrape lies in its ability to form a considerable seed bank in soil. A management or eradication program must aim at reducing this seed bank, in order to minimize the production of new seeds and their dispersal to new sites.

Recent approaches are necessary to control parasitic weeds of the genus Orobanche. The broomrape fly, Phytomyza orobanchia Kaltenbach (Diptera, Agromyzidae), is particularly suitable for biological control since it is of oligophagous feeding, in the larval stage, only on Orobanche species. In total, of the 140 Orobanche spp. described, the occurrence of $P$. orobanchia was reported from 21 species. The use of $P$. orobanchia in biocontrol 
of Orobanche is based on inundative releases at the time of Orobanche emergence. The larvae of the fly mine in Orobanche shoots, capsules, and intervene at the sensitive reproductive stage of Orobanche. Hence, the reduction of Orobanche seed production prevents supplementary infestation and dissemination. The advantage of this control approach is its compatibility to all crop/Orobanche associations and that it can easily be combined with other control methods (Kroschel and Klein 2002).

In Egypt, biological control trials of the weed $\mathrm{O}$. crenata were conducted by Kolaib (1991), Al-Eryan (1996), Al-Eryan and Zaitoun (1998), Zaitoun and Al-Eryan (1999), and Abu-Shall (2001). Although of the effectiveness of Phytomyza releases in reducing Orobanche seed production can reach $(91.73 \%)$, the already infested soil in addition to new accumulated seeds will cause further infestations throughout the successive seasons. Biocontrol with $P$. orobanchia may be helpful in reducing further dissemination and infestation in light infested areas, and could be incorporated into an integrated control approach to reduce the seed bank in heavily infested soils (Rubiales et al. 2001). This effect can be substantially increased by massive propagation and releasing of the insect at the beginning of Orobanche flourishes as demonstrated by Klein et al. (2002).

In Egypt, Tawfik et al. (1976) studied the biology of $P$. orobanchia and found that the females insert their eggs in the Orobanche flower. The total number of deposited eggs was 32.93 eggs per female. The durations of development for the three larval instars lasted about 1.1, 1.93, and 2.22 days, respectively. The total larval period lasted about 5.3 days. The larvae feed on the immature seeds inside the capsule. Pupation takes place either in the capsules or in the stem. For pupation in the fruit, the mature larva bores into the enclosed seeds and tissues leaving a rounded thin membranous area on the pericarp through which the adult will emerge. At the end of season, the mature larva bores inside toward the stem to enter diapause till the next season. The estimated lifecycle from egg deposition to first egg laid in the following generation lasted 18.9 days (17-20 days).

Heat unit systems quantify the thermal environment of organisms and are commonly used in phenology models that relate organism growth and development to local weather/climate conditions. Several methods of calculating heat units have been developed and are presently used worldwide in phenology models. The accumulation of degree-days has become a useful tool in monitoring the emergence and development of insect populations (Jyoti et al. 2003).

The objective of the present study was estimating the number of annual generations of $P$. orobanchia, using growing degree-days at Alexandria region.

\section{Materials and methods}

Estimation of generation numbers of $P$. orobanchia

In faba bean fields, Orobanche spikes emerge aboveground on different growth stages from January until end of April 2015. To estimate the first generation of $P$. orobanchia, 40-50 flowering Orobanche spikes were randomly selected at the beginning of Orobanche emergence. Collected spikes were picked up from faba bean field in Nubaria region located at Sahara adjacent south Alexandria region, Egypt. Collected plants were transferred to the laboratory, placed in plastic containers, and then left to complete maturation under natural conditions. Three flowers or capsules were daily detached from each Orobanche spike and examined under stereomicroscope to record immature stages of $P$. orobanchia. Immature stages were classified into sequential developmental stages, i.e., egg, 1st, 2nd, and 3rd larval instars and pupae (Fig. 1) in conjunction with the three growth stages of Orobanche: GS 6, 65: fleshy spike (growth stage full flowering: $50 \%$ of flowers open, first petals may be fallen), GS 6, 69: semi-mature spike (growth stage, end of flowering: fruit set visible), and GS, 7, 79: mature spike (growth stage: nearly all fruits have reached final size normal) according to description of Hess et al. (1997) and Al-Eryan et al. (2003). Generation period was expressed as from egg to adult emergence. Percentage of Orobanche capsules infested with $P$. orobanchia was estimated daily.

After adult emergence of the first generation, new group (40-50) of flowering Orobanche plants were randomly collected from the faba bean field cultivated in Abees region, Alexandria to follow up development of the second generation. The same method was applied to determine the third and fourth generations of P. orobanchia. During the period of study, daily maximum and minimum temperatures were obtained from data of Egyptian Meteorological Authority station (E.M.A.S).

\section{Determination of growing degree-days}

Degree-days (DD) are used to measure the number of accumulated heat units above temperature threshold that are required for insect development. The first date at which P. orobanchia female laying the first egg in the Orobanche flower was considered as the beginning of calculation of the degree days accumulation (biofix date). The lower threshold temperature for development of $P$. orobanchiawas $12.5^{\circ} \mathrm{C}$, daily average (base temperature), calculated by Abu-Shall (2007) and used in the present study.

Calculating growing degree days (GDD) was applied according to Pruess (1983) and Fry (1983) as follows:

$$
\begin{gathered}
\text { Daily GDD }=[(\text { max temperature }+ \text { minimum temperature }) / 2] \\
\text {-base temperature }
\end{gathered}
$$

If the maximum temperature for the day never rises above the base temperature, then no development occurs 


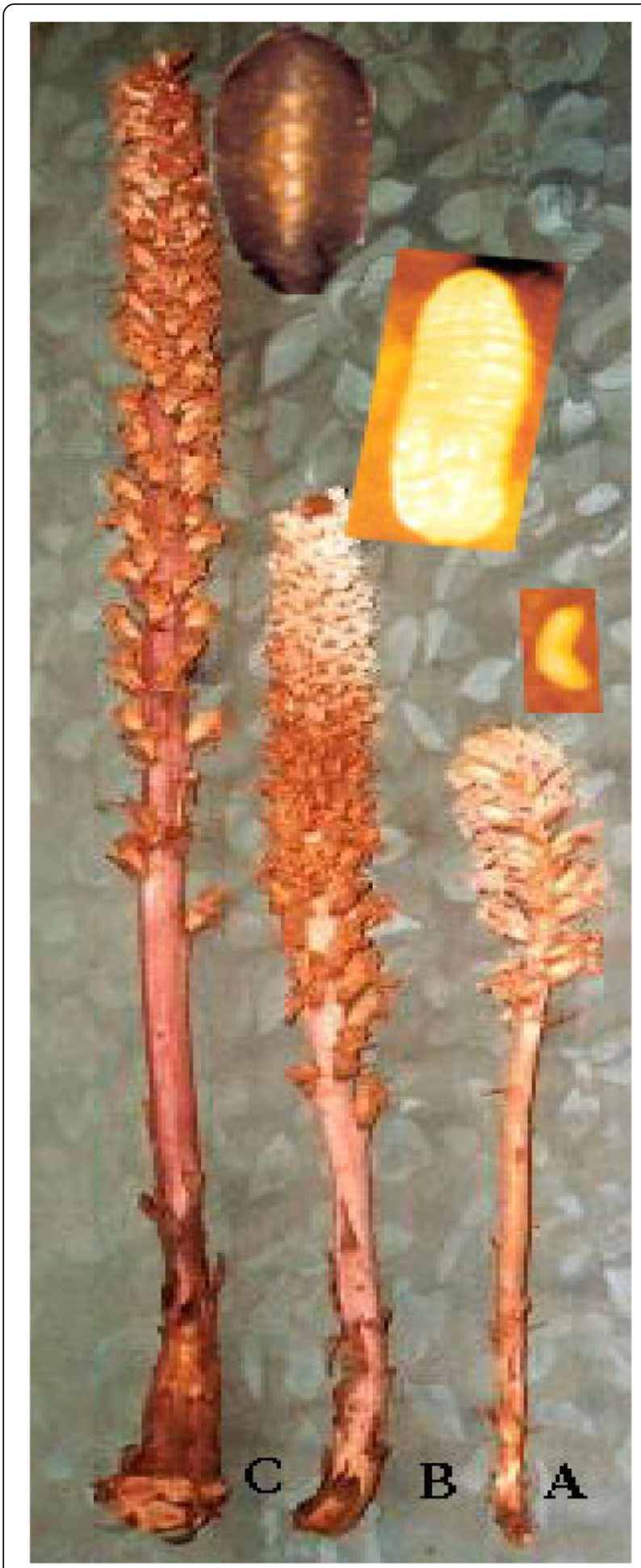

Fig. 1 Synchronization between phonological stages of O. crenata and immature stages of $P$. orobanchia

and zero degree-days accumulated (negative degree-day values are not calculated since the development of organisms does not continue when it is cold).
Prediction of $P$. orobanchia annual generations was carried out by determining the relationship between the thermal heat units, expressed as DD and development of $P$. orobanchia stages, expressed as percentage of infested capsules during the period from early January to late April 2015.

\section{Statistical analysis}

For statistical analysis, the correlation between degree-days and percentage of capsule's infestation with $P$. orobanchia were calculated, using least squares regression (Sokal and Rohlf 1973).

\section{Results and discussion}

Accumulated degree-days required for development of four generations of $P$. orobanchia in $O$. crenata spikes are presented in Table 1 and Fig. 2. Orobanche spikes were examined at the three growth stages: GS 6, 65 (flowering Orobanche), GS 6, 69 (semi-mature Orobanche), and GS 7, 79 (mature Orobanche) through all generations of $P$. orobanchia. Results showed that eggs of $P$. orobanchia started to be laid on Jan. 11 at 0.5 accumulated degree-days. This was considered as the date of starting the development of $P$. orobanchia and calculation of accumulated degrees-days. Development of Phytomyza immature stages (from egg to adult emergence) required 103.5 accumulated degree-days through 31 days (from Jan. 11 to Feb. 10). Infestation percent of Orobanche capsules with P. orobanchia reached the maximum $(25.4 \%)$ by the end of this generation. This generation appeared in faba bean fields cultivated early in Sahara regions adjacent to Alexandria region.

Accumulated degree-days required for development for the second generation of $P$. orobanchia in O. crenata spikes were indicated in Table 1 and Fig. 2. Results showed that the eggs of $P$. orobanchia were laid on Feb. 20 at 139.5 DD. Development of Phytomyza immature stages (from egg to adult emergence) required 90 accumulated day-degrees through 20 days (from Feb. 20 to Mar. 11). Infestation percent of Orobanche capsules with $P$. orobanchia reached the maximum $(50 \%)$ by the end of this generation.

In the third generation, the eggs of $P$. orobanchia were laid on Mar. 12 at 226.5 DD. Development of Phytomyza immature stages (from egg to adult emergence) required 79 accumulated degrees-days through 18 days (from Mar. 12 to Mar. 29). Percentage of infestation to Orobanche capsules with $P$. orobanchia reached the maximum (64.7\%) by the end of this generation (Table 1 and Fig. 2).

Degree-days accumulations required for development of the fourth generation are presented in Table 1 and Fig. 2. Results showed that the eggs of $P$. orobanchia were laid on Mar. 30 at 308 DD. Development of Phytomyza immature stages (from egg deposition to adult emergence) required 93.5 accumulated degrees-days through 18 days 
Table 1 Develoment of Phytomyza. orobanchia generations synchronized with three growth stages of Orobanche crenata spikes in Alexandria region

\begin{tabular}{|c|c|c|c|c|c|}
\hline Generations & Date 2015 & Orobanche growth stage & Phytomyza growth stages & $\%$ infested capsules & Accumulated Degree-Days \\
\hline \multirow[t]{4}{*}{ I } & Jan., 11 & Flowering & Eggs & 2.77 & 0.5 \\
\hline & Jan., 18 & & Larvae & 5.55 & 11 \\
\hline & Jan., 29 & Semi-mature & Pupae & 12.25 & 52.5 \\
\hline & Feb., 10 & Mature & Pupae & 25.4 & 116.5 \\
\hline \multirow[t]{4}{*}{$\|$} & Feb., 20 & Flowering & Eggs & 1 & 139.5 \\
\hline & Feb., 23 & & Larvae & 15.5 & 156 \\
\hline & Mar., 4 & Semi-mature & Pupae & 16.5 & 187.5 \\
\hline & Mar., 11 & Mature & Pupae & 50 & 224 \\
\hline \multirow[t]{4}{*}{ III } & Mar., 12 & Flowering & Eggs & 5.5 & 226.5 \\
\hline & Mar., 13 & & Larvae & 7.5 & 229 \\
\hline & Mar., 16 & Semi-mature & Pupae & 36.2 & 240 \\
\hline & Mar., 29 & Mature & Pupae & 64.4 & 304 \\
\hline \multirow[t]{4}{*}{ IV } & Mar., 30 & Flowering & Eggs & 33.3 & 308 \\
\hline & Mar., 31 & & larvae & 61.6 & 313.5 \\
\hline & Apr., 3 & Semi-mature & Pupae & 66.6 & 333 \\
\hline & Apr., 14 & Mature & Pupae & 100 & 463.5 \\
\hline
\end{tabular}

(from Mar. 30 to April 14). Infestation percent of Orobanche capsules with $P$. orobanchia reached the maximum $(100 \%)$ by the end of this generation, most pupae entered summer diapause up to the new flourishing season.

A linear regression equation provided a good mathematical description of the effect of degree-days on the infestation of Orobanche capsules with P. orobanchia (Fig. 3). Percentage of infested Orobanche capsules positively increased by increasing accumulated degree-days. Where the regression coefficient $\left(R^{2}=0.964\right)$ was significant.
Under field conditions, adults of P. orobanchia are common from the beginning of Orobanche flourishing. The mated females search for suitable buds and flowers to lay their eggs. In this context, Klyueva and Pamukchi (1978) in Moldova noticed that adults of P. orobanchia appeared in the field from the beginning of Orobanche emergence, and hatching took place at a mean air temperature of $20^{\circ}$ $\mathrm{C}$ and 530 accumulated degree-days. In Ukraine, Kott (1969) observed adults at mean temperatures of $22-23^{\circ} \mathrm{C}$ from the beginning of emergence of Orobanche. Also, in the former USSR, Tsybul'skaya et al. (1978) found that the

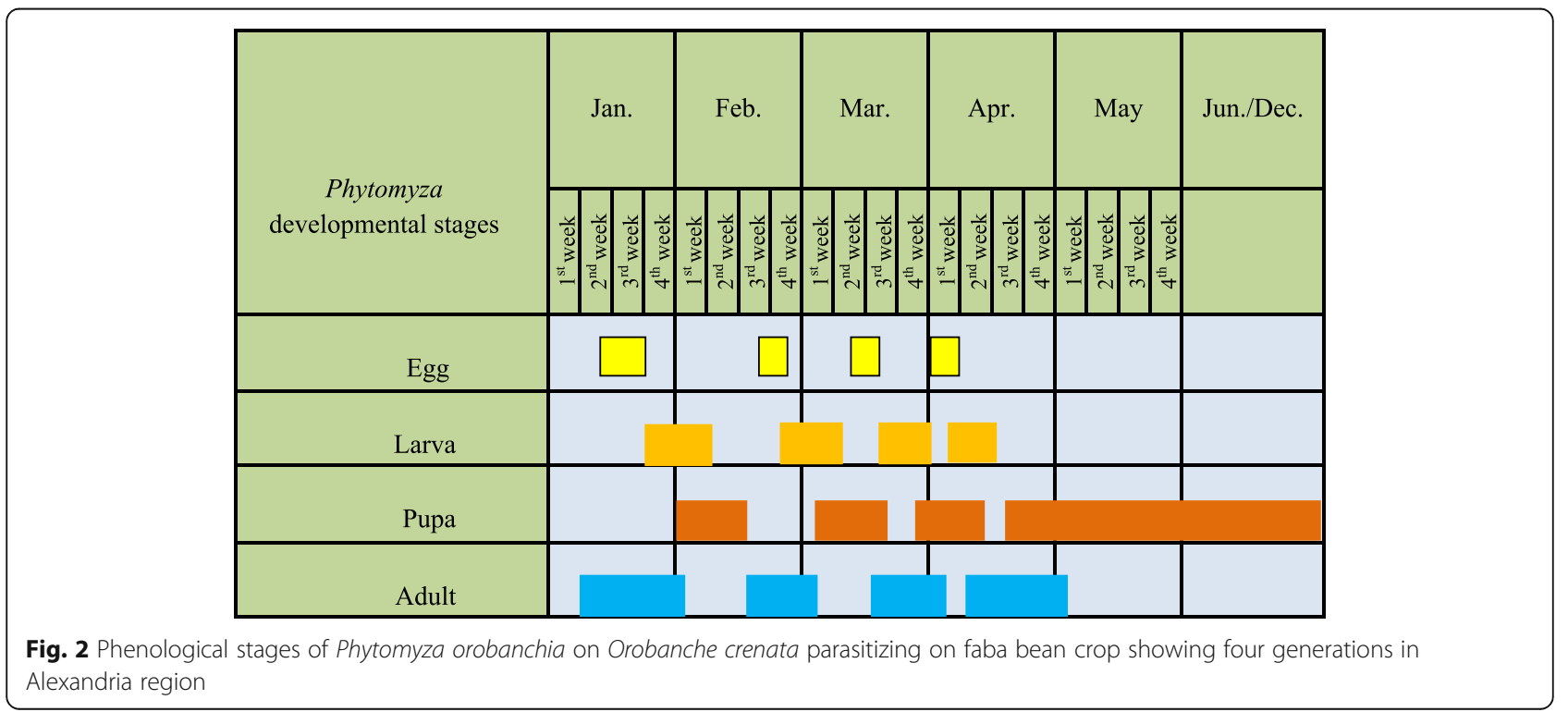




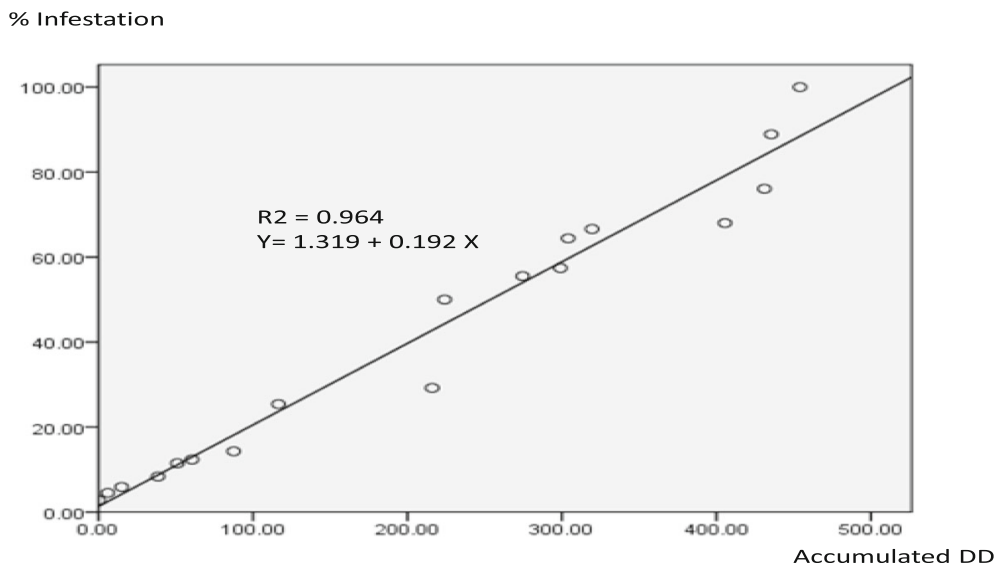

Fig. 3 Regression line of accumulated degree-days and percentages of infested Orobanche capsules with P. orobanchia

flies of $P$. orobanchia overwinter in the pupal stage and the adults emerge when the temperature reaches $20^{\circ} \mathrm{C}$. In the same subject, $P$. orobanchia was affected by high and low temperature degrees in Uzbekistan, where Kurbanov (1970) reported that up to (35\%) of the pupae were destroyed by temperature under zero during hard winter. While low temperatures during winter can cause a high mortality of Phytomyza pupae (Lekic 1970). In the south of Ukraine, there are 2-3 generations in a year and each requiring 20-36 days for development. Most of the larvae moved to the underground parts of the Orobanche stems for pupation (Tsybul'skaya et al. 1978).

Also, unsuitable temperature forced the Phytomyza larvae to enter diapause in the pupal stage. Klyueva and Pamukchi (1980) reported that the percentage of the diapause for the three generations took place as: 2-22, 3387 , and almost $100 \%$ for first, second, and third generations, respectively. But most of the diapaused pupae emerged in the subsequent year and only $13 \%$ remained in a prolonged diapause for longer than 1 year. Sometimes, the diapause lasts 4 years in order to cover the absence of host-plant. Diapause is induced by a day-length of less than $14 \mathrm{~h}$, but the optimum photoperiod for the midge's development was $16 \mathrm{~h}$. The percentage of diapaused pupae increased with declining temperatures to 16 and $8{ }^{\circ} \mathrm{C}$. In Syria, Linke et al. (1991) studied the relationship between the appearance of P. orobanchia and Orobanche spp. The first appearance of the fly coincided with the first emergence of the Orobanche shoots. They suggested that its arrival was most probably related to temperature. Al-Eryan (1996) recorded three generations of P. orobanchia per year under field conditions. The first and second generations required about 3 weeks for development, while the third one required 2 weeks. The present study indicated that additional generation appeared early in January and February 2015 in faba bean fields cultivated in Sahara regions at daily mean temperature $15.1{ }^{\circ} \mathrm{C}\left(11.5-21.0^{\circ} \mathrm{C}\right)$.
Since the temperature is considered as an important environmental factor that affects the rate of development of the insect and controlled the success of the insect to survive in a given temperature, it was particularly as practical point of view interesting for economic insects to obtain a useful and good forecast and prediction system for insect population (Wagner et al. 1984). The degree-days (DD) forecasting method has been successfully used in the past for forecasting several economic pests. In the formulation of forecasting models, developmental data from a range of temperatures help to determine the insect developmental threshold (Herms 1998).

Similar studies were conducted on related species of agromized flies. Petitt et al. (1991) and Petitt and Wietlisbach (1994) reported that (99.9\%) of Liriomyza sativae emerged from leaves after 95 DD (threshold temperature, $10{ }^{\circ} \mathrm{C}$ ). Millia (2005) stated that the Holly leaf miner (Phytomyza ilicis) larvae and adults needed 246 DD, while native holly leaf miner (Phytomyza iliciola) larvae and adults needed 192 and 298 DD.

\section{Conclusion}

Results of the present study certified four generations for $P$. orobanchia on $O$. crenata in faba bean field. Knowledge of Phytomyza activity will provide a prediction for adult emergence and subsequent egg laying and potential damage by larvae as infestation percent of Orobanche capsules through the successive generations. This may help the biological control programs to justify the required numbers of Phytomyza and adequate time for releases to obtain the maximum destruction of Orobanche seeds. The constructed model may be used in predicting Orobanche capsule infestation with P. orobanchia, but the validity of the model should be carried out using new field observations through several seasons. 


\section{Abbreviations}

DD: Degree-days; GDD: Growing degree-days

\section{Acknowledgements}

The authors express deep thanks to Prof. Dr. Fatthalla Mohammad Zaitoun, Professor of flowering Parasitic Plants, Department of Phytopathology, Faculty of Agriculture, Alexandria University, for helping in revising the manuscript.

\section{Funding}

There is no funding source to be declared for this study.

\section{Availability of data and materials}

Data will not be shared.

\section{Authors' contributions}

All authors read and approve the manuscript or all authors approve to publication.

\section{Ethics approval and consent to participate}

Not applicable.

\section{Consent for publication}

Not applicable.

\section{Competing interests}

The authors declare that they have no competing interests.

\section{Publisher's Note}

Springer Nature remains neutral with regard to jurisdictional claims in published maps and institutional affiliations.

\section{Received: 16 March 2018 Accepted: 16 October 2018}

Published online: 04 December 2018

\section{References}

Abu-Shall AMH (2001) Applied study on utilization of Orobanche fly and other biotic agents in the biological and integrated management of broom-rape and other noxious weeds, M.Sc. Thesis. Faculty of Agriculture, Alexandria University, p 125

Abu-Shall, Amany M.H. (2007). Investigations on certain factors affecting the efficacy broomrape fly associated with the biological and integrated management of faba bean broomrape. Ph.D. thesis, Faculty of Agriculture, Alexandria University,134pp

Al-Eryan, M.A.S. (1996). Role of certain bioassociates in the biological and integrated pest management Phytomyza orobanchia Kalt. and Glyphosate as biochemical control of agents of Orobanche crenata Forsk. Ph.D. Thesis, Faculty of Agriculture, Alexandria University, $143 \mathrm{pp}$

Al-Eryan MAS, Altahtawy MMM, El-Sherief HK, Abu-Shall AMH (2003) Phenological stages of the parasitic weeds Orobanche crenata Forsk. as a guide for collecting a parasitoid-free Phytomyza orobanchia Kalt. Egypt J Biol Pest Control 13(1\&2):105-109

Al-Eryan MAS, Zaitoun FMF (1998) Efficiency of the Dipteran, Phytomyza orobanchia and rot fungi as biocontrol agents of broomrape, Orobanche crenata in Egypt. Submitted to Vlth European Congress of Entomology, Ceske Budejovice, August 23-29, 1998, Czeck Republic, Book of Abstracts, pp 493-494

Fry, K.E. (1983). Heat-unit calculations in cotton crop and insect models.USDAARS advances in agricultural technology, Western Series No. 23, Oakland CA, 23 pp. (c.f. Thomas, 1997)

Hassanein, E.E.; Ellan, M.E.; Abo, K.G. and El-Enin, R.A. (1996). Orobanche crenata Forsk. survey and control in Faba bean (Vicia faba L.) and Peas (Pisum sativa L.). Sixth International Parasitic Weed Symposium, Cordoba Spain, 16-18

Herms, A.H. (1998). Ornamental plants. Annual reports and research reviews of entomology. Ohio Agriculture Research Development Centre, Special Circular, 165-169

Hess, M.; Barralis, G.; Bleiholder, H.; Buhr, L.; Th-Eggers; Hack, H. and Stauss, R. (1997) Use of the extended BBCH scale-general for the descriptions of the growth stages of mono- and dicotyledonous weed species. Weed Res 37: 433-441

Jyoti JL, Shelton AM, Barnard J (2003) Evaluation of degree day and Julian- day logistics models in predicting cabbage maggot (Diptera: Anthomyiidae) emergence and flight in upstate New York. J Entomol Sci 38(4):535-532
Klein, O.; Kroschel, J and Elzein, A. (2002). Status quo of Phytomyza orobanchia research. Parasitic plant management in sustainable agriculture WG2+WG4 +MC meeting Obermarchtal, Germany 25-27

Klyueva MP, Pamukchi GV (1978) Broomrape midge the natural enemy of broomrape in Moldavia. Izvestiya Akademii Nauk Moldaveskoi SSR, Seriya Biologiches Kikhi Khimicheskikh Nauk 4:21-25

Klyueva MP, Pamukchi GV (1980) The diapause of the phytophage Phytomyza and its causes. Sel'skokhozyaist vennaya Biologiya 15(3):396-400

Kolaib MO (1991) Biological control of the broomrape weed, Orobanche crenata Forsk., in Egypt Menoufia. J Agric Res 6(1):867-876

Kott, S.A. (1969). Biolgical control of broomrape. In: [Weeds and their control], Kolos, Moskva, USSR, 169-171. (c.f. Kroschel, J. and Klein, O. 1999)

Kroschel, J. and Klein, O. (2002). Biological control of Orobanche spp. in the Near East and North Africa by Inundative releases of the herbivore Phytomyza orobanchia. In integrated management of Orobanche in food legumes in the Near East and North Africa, 55-66

Kurbanov T (1970) The use of Phytomyza on the fields of Solchos. Biological control of the Egyptian broomrape in vegetables and melons. Sel, skoe Chozjajstvo Usbekistana 9:50

Lekic MB (1970) The role of the dipteran Phytomyza orobanchia Kalt. (Agromyzidae) in reducing parasitic phanerogam populations of the Orobanche genus in Vojvodina. Contemporary Agric 18(7/8):59-68

Linke K.H.; Weigand, S. and Saxena, M.C. (1991). Biological control of Orobanche. ICARDA, Legume program: Annual Report 231-233

Millia K (2005) Spatial/temporal model for survivability of pea leaf miner (Liriomyza huidobrensis) in warm climates: a case study in South Florida, USA. Eur J Sci Res 7(5):65-73

Petitt FL, Allen JC, Carl S (1991) Degree-day model for vegetable Leafminer (Diptera: Agromyzidae) phenology. Barfield Environ Entomol 20(4):1134-1140

Petitt FL, Wietlisbach DO (1994) Laboratory rearing and life history of Liriomyzasativae (Diptera: Agromyzidae) on Lima bean. Environ Entomol 23:1416-1421

Pruess KP (1983) Day-degree methods for pest management. Environ Entomol 12:613-619

Rubiales, D.; Moreno, M.T.; Kharrat, M.; Zermane, N. and Khalil, S. (2001). Broomrape (Orobanche crenata) control in sustainable agriculture. In: AEP (Ed.), Legumed Symposium Grain Legumes in the Mediterranean Agriculture. Rabat, pp. 25-27

Sokal RR, Rohlf FI (1973) Introduction to biostatistics. Freeman, San Francisco

Tawfik MFS, Awadallah KT, Shalaby FF (1976) Biology of Phytomyza orobanchia kalt. (Diptera: Aagromyzidae). Bull Soc Ent Egypte 60:53-64

Tsybul'skaya GN, Degtyarev BG, Fedoryak NA, Skoklyuk AN (1978) Determination of viability of Phytomyza puparia. Zascita Rastenij 5:29-30

Wagner TL, Wu HI, Sharpe PJ, Schoolfield RM, Coulson RN (1984) Modeling insect development rate: a literature review and application of a biophysical model. Ann Ent Soc Am 77:208-225

Zaitoun FMF, Al-Eryan MAS (1999) Loss assessment and forecasting work on plant diseases: 2-prediction of Orobanche crenata seed yield and its reduction due to Phytomyza orobanchia and rot fungi. In: Kroschel J, Abderabihi M, Betz $\mathrm{H}$ (eds) Advances in parasitic weed control at on-farm level. Vol. II. Joint Action to Control Orobanche in the WANA Region. Maragraf Verlag, Weikersheim, pp 185-195

Zaitoun, F.M.F.; Al-Menoufi, O.A. and Weber, H.C. (1991). Loss assessment and forecasting work on plant disease: 1- A new method for assessment of loss in Viciafaba through infection with Orobanche crenata.In: Wegmann, K. and L. J. Musselman (eds.), Progress in Orobanche Research. Eberhard-KarlsUniversitat, Tubingen, FRG, 167-184 